\title{
Perfil dos Idosos em um Projeto de Convivência e Lazer na Periferia de Fortaleza-CE
}

Pamplona, Ysabely de Aguiar Pontes; Mendes, Raquel Silveira; Peixoto, Gabrielle da Silva; Viana, Paulo Átila da Silva; Martins, Lourdes Conceição

\author{
Unisantos - ysabelypontes@hotmail.com
}

Introdução: no Brasil, a expectativa de vida aumentou no último meio século, proporcionando uma explosão demográfica de idosos no país. Concomitantemente, houve um aumento na prevalência de doenças crônico-degenerativas, uma vez que o próprio processo do envelhecimento é fator de risco para morbidades. Objetivo: Descrever o perfil de idosos cadastrados em um projeto de convivência e lazer na periferia de Fortaleza/CE. Metodologia: Estudo descritivo, transversal e com abordagem quantitativa, que descreve o perfil epidemiológico e socioeconômico de idosos cadastrados em um projeto de convivência e lazer localizado no bairro Canindezinho na cidade de Fortaleza-CE-Brasil. Foram entrevistados 24 idosos de agosto a outubro de 2013, para isso utilizou-se de um instrumento modificado do padrão original Brazil Old Age Schedule - BOAS. Os dados encontrados foram processados e analisados mediante a utilização de estatística descritiva. Resultados e Discussão: Os resultados revelaram que $87,5 \%$ são do gênero feminino; 89\% são aposentados; 83,3\% possuem baixo poder aquisitivo; 58,3 têm baixo nível de escolaridade; $75 \%$ têm renda mensal entre um a dois salários mínimos; $79 \%$ tem uma percepção positiva da sua saúde geral; 91,7\% apresentam algum tipo de doença e fazem uso de medicamento diariamente. Além disso, todos os entrevistados apresentaram alto grau de autonomia e independência. Conclusão: o conhecimento das características dos idosos é fundamental para o estabelecimento de políticas públicas de promoção à saúde, favorecendo o cuidado integral, individualizado e preventivo. Além disso, pode haver variações nas ações de enfrentamento, quando a população encontra-se em situação social distinta.

Pamplona, Ysabely de Aguiar Pontes; Mendes, Raquel Silveira; Peixoto, Gabrielle da Silva; Viana, Paulo Átila da Silva; Martins, Lourdes Conceição. Perfil dos Idosos em um Projeto de Convivência e Lazer na Periferia de Fortaleza-Ce. In: Anais do Congresso Internacional de Humanidades \& Humanização em Saúde [= Blucher Medical Proceedings, num.2, vol.1]. São Paulo: Editora Blucher, 2014. ISSN 2357-7282 DOI 10.5151/medpro-cihhs-10824 